\title{
ESR and NMR studies provide evidence that phosphatidyl glycerol specifically interacts with poxvirus membranes
}

\author{
Jean-Claude Debouzy ${ }^{1}$, David Crouzier ${ }^{1 *}$, Anne-Laure Favier$^{2}$, Julien Perino ${ }^{2}$
}

\begin{abstract}
Background: The lung would be the first organ targeted in case of the use of Variola virus (the causative agent of smallpox) as a bioweapon. Pulmonary surfactant composed of lipids (90\%) and proteins (10\%) is considered the major physiological barrier against airborne pathogens. The principle phospholipid components of lung surfactant were examined in an in vitro model to characterize their interactions with VACV, a surrogate for variola virus. One of them, Dipalmitoyl phosphatidylglycerol (DPPG), was recently shown to inhibit VACV cell infection.

Results: The interactions of poxvirus particles from the Western Reserve strain (VACV-WR) and the Lister strain (VACV-List) with model membranes for pulmonary surfactant phospholipids, in particular DPPG, were studied by Electron Spin Resonance (ESR) and proton Nuclear Magnetic Resonance ('H-NMR). ESR experiments showed that DPPG exhibits specific interactions with both viruses, while NMR experiments allowed us to deduce its stoichiometry and to propose a model for the mechanism of interaction at the molecular level.

Conclusions: These results confirm the ability of DPPG to strongly bind to VACV and suggest that similar interactions occur with variola virus. Similar studies of the interactions between lipids and other airborne pathogens are warranted.
\end{abstract}

\section{Background}

Membrane contacts occur at the very early steps of pulmonary viral infection [1]. This is especially important under circumstances where aerosol dispersion of viruses occurs readily [2] and an aerosol respiratory contamination would be an easy way for a biological agent to cause massive casualties. One of the initial and essential steps in a pulmonary infection is the crossing of the surfactant barrier separating the respiratory lumen from cells lining alveoli. The interactions of vaccinia virus (VACV, a surrogate model of variola) with surfactant phospholipid components, is the focus of the present work. Pulmonary surfactant (PS) is a complex mixture of lipids (90\%) and proteins (10\%), participating in reducing surface tension at the air-liquid interface and in protecting the lung against pathogens as part of the innate immune system [3-6]. The abundance and

\footnotetext{
* Correspondence: david.crouzier@wanadoo.fr

'Unité de biophysique cellulaire et moléculaire, CRSSA-IRBA, 24 avenue des maquis du Grésivaudan, 38702 La Tronche cedex France

Full list of author information is available at the end of the article
}

physiological importance of several phospholipid species (ie Phosphatidylcholine, PC; Dipalmitoyl phosphatidylcholine, DPPC; Dipalmitoyl phosphatidylglycerol, DPPG) led us to select several of them in the study of virus interactions with surfactant $[3,4,7]$. To date, only a few studies have described the role of surfactant phospholipids in virus entry. In the case of adenoviruses, the role of DPPC contained in lung surfactant or expressed by lung cells was found to increase the penetration of a respiratory adenovirus without involving any specific receptors [8]. The specific interaction of an enteric adenovirus strain with different phospholipids contained in the gastrointestinal surfactant has also been characterized [9]. Considering the importance of phospholipids in lung surfactant and the hypothesis that specific virusphospholipid interactions may occur we were interested in gaining an understanding of VACV entry into alveolar epithelium. Recently, we showed that DPPG interacts with VACV and that DPPG incorporated in Small Unilamellar Vesicles (SUV-DPPG) inhibits VACV cell infection, unlike other phospholipids tested [10]. In this

\section{C) Biomed Central}


study, we first focused on the major components of phospholipid lung surfactant and two viral strains were selected (the virulent lethal mouse neurotropic Western Reserve strain (VACV-WR) [11] and the Lister strain (VACV-List), previously used in Europe as a smallpox vaccine). In this in vitro study, electron spin resonance (ESR) and nuclear magnetic resonance (NMR) methods were used to identify and draw mechanistic data of virus phospholipid interactions, using small unilamellar vesicles (SUV), previously established as membrane models [12].

\section{Methods}

\section{Virus preparation and inactivation}

The vaccinia virus Western Reserve strain (VACV-WR), obtained from the ATCC (ATCC VR-119), and the firstgeneration Lister smallpox vaccine (VACV-List), provided by the French health authorities, were produced in BHK-21 cells and titrated in Vero cells. In order to use these viruses for NMR experiments, solvents were replaced by deuterated solvents. Viruses purified in water based solvents were diluted in deuterated PBS and then purified using deuterated sucrose gradients [13].

For safety reasons, viruses were inactivated for some experiments using a previously described protocol [14]. Briefly, $100 \mu \mathrm{L}$ virus was incubated with $1 \mu \mathrm{L}$ Psoralen (Sigma, $1 \mathrm{mg} / \mathrm{mL}$ in Deuterated DMSO) and exposed for 1 hour to UV light $(365 \mathrm{~nm})$ in a 48 well tissue culture plate. For the samples dedicated to NMR experiments, the same preparation was used except that all solvents (water, DMSO....) were deuterated to avoid spectrum saturation related to an excessive contribution of the solvent resonances. The final amount of virus was 4.5.10 9 PFU in a $500 \mu \mathrm{L}$ sample.

\section{Small unilamellar vesicles (SUV)}

Freeze-dried phospholipids were dissolved in chloroform at the desired molar concentration. Unsaturated phospholipids (DPPC or DPPG) were added to a $2 \mathrm{mM}$ PC solution in a $30 \%$ final ratio. The mixture was dried overnight under vacuum. The lipid film was hydrated with water and subjected to water bath sonication for 2 hours at different temperatures depending on the fusion temperature of the lipids present in the mixture. SUV formation was ascertained by the observation of a ${ }^{1} \mathrm{H}$-NMR classical spectrum, with a typical linewidth of chain terminal methyl groups of $15 \mathrm{~Hz}$ or less [15]. For the NMR experiments recorded in the presence of dipalmytoyl phosphatidylglycerol (DPPG), the lipid concentration of the stock solution was $2.7 \mathrm{mM}$ in $\mathrm{D}_{2} \mathrm{O}$.

\section{ESR Experiments}

SUV/virus interactions were assessed by Electron Spin Resonance (ESR) spin labeling experiments. Inactivated virus $\left(5 \mu \mathrm{L}, 9 \times 10^{9} / \mathrm{mL}\right)$ was labeled with the 5 -nitroxide stearate (5NS) probe (Sigma France), (5 min incubation at $\left.37^{\circ} \mathrm{C}\right)$. This probe is composed by a fatty acid $(\mathrm{C} 16)$ and a stabilized free radical. The probe self incorporates into membranes and provides information of label motional freedom in the system. Then the specific SUV solution $(50 \mu \mathrm{L}$ at $2 \mathrm{mM})$ was added to the mix and incubated for 90 minutes at $37^{\circ} \mathrm{C}$. The beginning of the kinetics was triggered by addition of $\mathrm{C}$ Vitamin (L-ascorbic acid, $15 \mu \mathrm{L}, 0.2 \mathrm{M}$ ). C Vitamin is a well known free radical scavenger. The decrease of the ESR signal could be linked to the accessibility of the probe to the $\mathrm{C}$ Vitamin, so a rapid decrease implies very few SUV/Virus interactions.

Five minutes after $C$ vitamin addition, the kinetics were recorded on an ESP 380 Brucker apparatus. Spectra were acquired in time sweep mode using static field, determined at the central line maximum amplitude of the T0 spectrumunder in EPR continuous wave mode $(3428 \mathrm{G})$. The instrument parameters were microwave power at $10 \mathrm{~mW}$, modulation frequency at $100 \mathrm{kHz}$, modulation amplitude at $2.53 \mathrm{G}$ and receiver gain at $6.30 \times 10^{4}$. Each sample was scanned 3 times under a controlled temperature $(300 \mathrm{~K})$ with the following acquisition parameters: Time constant $163.84 \mathrm{~ms}$, conversion time $163.84 \mathrm{~ms}$. All kinetics were recorded for 671 seconds and all experiments were performed in triplicate. For most ESR curve fitting, an exponential fit was used and considered as correct for values of $R$ exceeding 0.95 . In the remaining cases, more complex functions had to be used and the fit on 671 data points was directly validated by a $\chi^{2}$ test when the calculated value did not exceed 4 [16].

\section{NMR Experiments}

${ }^{1} \mathrm{H}$-NMR spectra were recorded at $295 \mathrm{~K}$ on an AM400 Bruker spectrometer at $400 \mathrm{MHz}(9.4 \mathrm{~T})$, using a presaturation sequence for water resonance suppression. The spectral width was $6000 \mathrm{~Hz}(15 \mathrm{ppm})$ recorded on $32 \mathrm{~K}$ data acquisition points with a recycling delay of $1 \mathrm{~s}$. Each spectrum was recorded using 80,000 scans.

\section{Results and discussion}

\section{ESR experiments: specificity of DPPG-VACV interactions}

A typical ESR spectrum of the 5-nitroxide stearate (5NS) label is recorded under free motion conditions (Figure 1A) and in the presence of small unilamellar vesicles (SUV), composed of PC (SUV-PC) (Figure 1B). Here it is noteworthy to recall some basic concepts required to draw any interpretation of such spectra. Each nitroxide group of the $5 \mathrm{NS}$ label bears a single $\mathrm{NO}^{\circ}$ free radical, chemically stabilized by the surrounding methyl groups of the nitroxide. Under the magnetic resonance conditions (i.e. a $9.71 \mathrm{GHz}$ radiofrequency, a magnetic screening on a 100 Gauss 


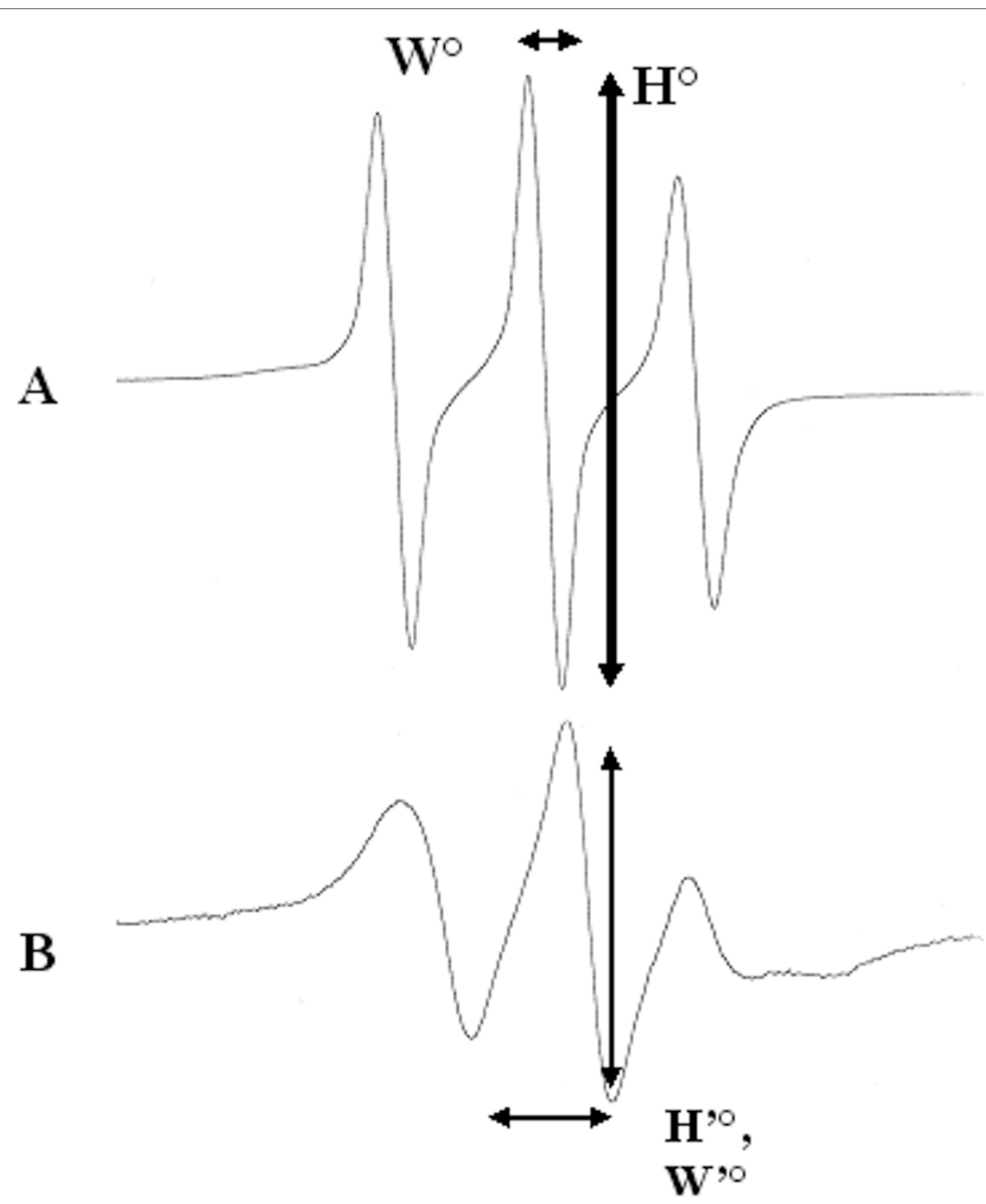

Figure 1 Typical ESR spectra. ESR spectra was recorded (295 K) under free motion conditions (A) and in the presence of motional limitation by interactions with lecithin vesicles (B). Respective linewidth $\left(\mathrm{W}^{\circ} \mathrm{W}^{\prime \circ}\right)$ and peak to peak height $\left(\mathrm{H}^{\circ} \mathrm{H}^{\prime \circ}\right)$ are labeled with arrows.

window), and due to hyperfine spin coupling, this group gives rise to 3 distinct lines. At this step, the spectral information used in this paper are:

- Spectral magnitude/intensity which at a first approximation is directly related to the number of spins present in the sample, which itself is related to the $5 \mathrm{NS}$ concentration.

- The magnitude of the resonance is in fact also dependent on the line width $\left(\mathrm{W}^{\circ}\right)$. For a given spin system, the product of $\mathrm{W}^{\circ}$ by the peak height $\left(\mathrm{H}^{\circ}\right)$ is a constant. This means that any line broadening will result in $\mathrm{H}^{\circ}$ intensity reduction (e.g. $\mathrm{H}^{\circ}$ and $\mathrm{W}^{\circ}$ in Figure $\left.1 \mathrm{~B}\right)$.
- $\mathrm{W}^{\circ}$, theoretically close to zero in ideal systems (free motion, no interaction or inhomogeneity) will broaden under two main circumstances, motional restriction/relaxation and exchange. The former is illustrated in Figure 1A, where resolved lines are detected on the spectrum of free 5NS while broader and less intense lines are detected on the motionally restricted 5NS embedded in the membrane (Figure $1 B)$. The latter observation results from the simultaneous existence of spins differing by their motional freedom. If the exchange is slow, the two components give rise to separate contributions (intermediate and fast exchanging systems only allow the 
detection of an average value of $\mathrm{H}^{\circ}$ and $\mathrm{W}^{\circ}$ ) from those of the two components.

- The magnitude of a spectrum is difficult to determine so its peak height measurement is generally used (in fact the peak to peak height, labeled $\mathrm{H}^{\circ}$ ). Any spin label reduction or destruction results in a proportional diminution of this value if the line width is kept constant. Thus, the time course of the central line height was recorded in the following experiments while controlling the line width before any interpretation of the data.

\section{Time course of $5 \mathrm{NS}$}

\section{Phospholipid systems (SUV)}

After incubation of the spin label with SUV alone, a typical spectrum of $5 \mathrm{NS}$ in the membrane was observed, providing the reference intensity and linewitdh. Also, the absence of a resolved line ensured that the entire label was incorporated in the bilayer and that no free spin label remained in the bulk. The addition of ascorbate (Vitamin $\mathrm{C}$, VitC) results in the reduction of the nitroxide, which can be visualized by a reduction in intensity. As the penetration is progressive and intramembrane motion of the label occurs, the time course curve presented in Figure 2A is easily fitted by an exponential function, as presented in Figure $3 \mathrm{~A}$ and the associated table. This time dependence was found for all of the pure SUV systems with time constants of the same order of magnitude.

\section{$D P P C, P C$, Sulfatide, and VACVs}

Coincubation of viruses with SUV and $5 \mathrm{NS}$ prior to VitC addition resulted in spectra similar to those recorded in the presence of SUV-5NS alone (peak height and line width were very close). Furthermore, the addition of ascorbate induced a similar time dependence of peak intensity reduction as testified by similar time constants of the exponential curves (table 1).

\section{DPPG and VACVs}

The same observation was made when SUV-DPPG were used without any virus. In contrast, co-incubation of SUV with 5 NS labeled virus resulted in a distinct time dependence. An initial increase in signal intensity relative to the reference intensity was noted when SUV were added suggesting that either 5NS was less motionally restricted and/or that exchanges had occurred. This was supported by a initial value for $\mathrm{W}^{\circ}$ of 4.7 Gauss, which increased to 6 Gauss at the maximum of the curve. At this time point VitC was present in the bulk. Longer time recordings led to a monoexponential decrease of the signal intensity with similar time constants as those observed for the other samples. Finally, the entire recording could not be fitted by a single exponential but required a diphased cosine component in addition to the exponential decrease (see Figure $3 \mathrm{~B}$ and table 1). The time course recordings for samples with VACV-List or VACV-WR were similar even if the initial rise was more marked and the cosine parameters different when the VACV-List variant was used.

\section{${ }^{1} \mathrm{H}-\mathrm{NMR}$ : mechanism of DPPG-VACV interaction Spectrum of poxvirus, $\mathrm{D}_{2} \mathrm{O}$}

The spectrum displayed in Figure 2 (line A, right) appears as broad overlapping lines and relatively resolved resonances that preclude any clearcut interpretation. On such a spectrum, only the mobile superficial groups produce resolved lines, while strongly immobilized and/or embedded groups are not detected or produce the extremely broad contributions. A special region of interest is presented on the left trace of Figure 2A. Except for three multiplets at 5.2, 5.4 and $5.55 \mathrm{ppm}$, the 5-6ppm is free of any broad contribution.

\section{DPPG addition}

Increasing amounts of SUV-DPPG (2.7 mM, $\left.\mathrm{D}_{2} \mathrm{O}\right)$ were added and similar spectra were recorded as for pure viruses. Up to $50 \mu \mathrm{L}$, no clear spectral modification was observed. Higher amounts allowed the detection of a very broad line of $250 \mathrm{~Hz}$ width whose magnitude increased with SUV concentration (Figure 2B).

Observation of the spectrum of pure SUV-DPPG (Figure 2D, expanded on the left column) showed that the only resonance in this spectral region is attributed to the glycerol methynic proton of the headgroup. However, such a resonance is located at $5.3 \mathrm{ppm}$ and has only a $20 \mathrm{~Hz}$ linewidth, in agreement with the mobility and small size of SUV $(10 \mathrm{~nm})$. Such a feature could be related to lipid immobilization which may increase the linewidth and a change in the magnetic shielding of $\mathrm{CH}$ proton (e.g. due to interactions with the lipidic environment).

Further evidence was obtained when supplementary amounts of DPPG were added. With $75 \mu \mathrm{L}$ SUV, a third line was detected, identical to that of pure SUV with DPPG (compare Figure 2C with respect to 2D), whose magnitude increased with increasing amounts of DPPG. On the other hand, the broad contribution at $5.5 \mathrm{ppm}$ remained unaffected. The SUV concentration dependence of the different contributions and linewidths are shown in Figure 4 . This clearly suggests that $i$ ) the broad line observed at "the low concentration" results from DPPG-VACV interactions $i$ i) that a saturation occurred for higher concentrations, leading to a major contribution of free SUV. This hypothesis is also supported by the markedly constant values of the linewidths of the two broad contributions (i.e 250 and $45 \mathrm{~Hz}$ ). No other information could be drawn from spectral subtractions between spectra of pure and DPPG-associated viruses in order to distinguish between overlapping of virus and lipid resonances. However, the different resonances observed in the 5-6 ppm region undoubtedly 


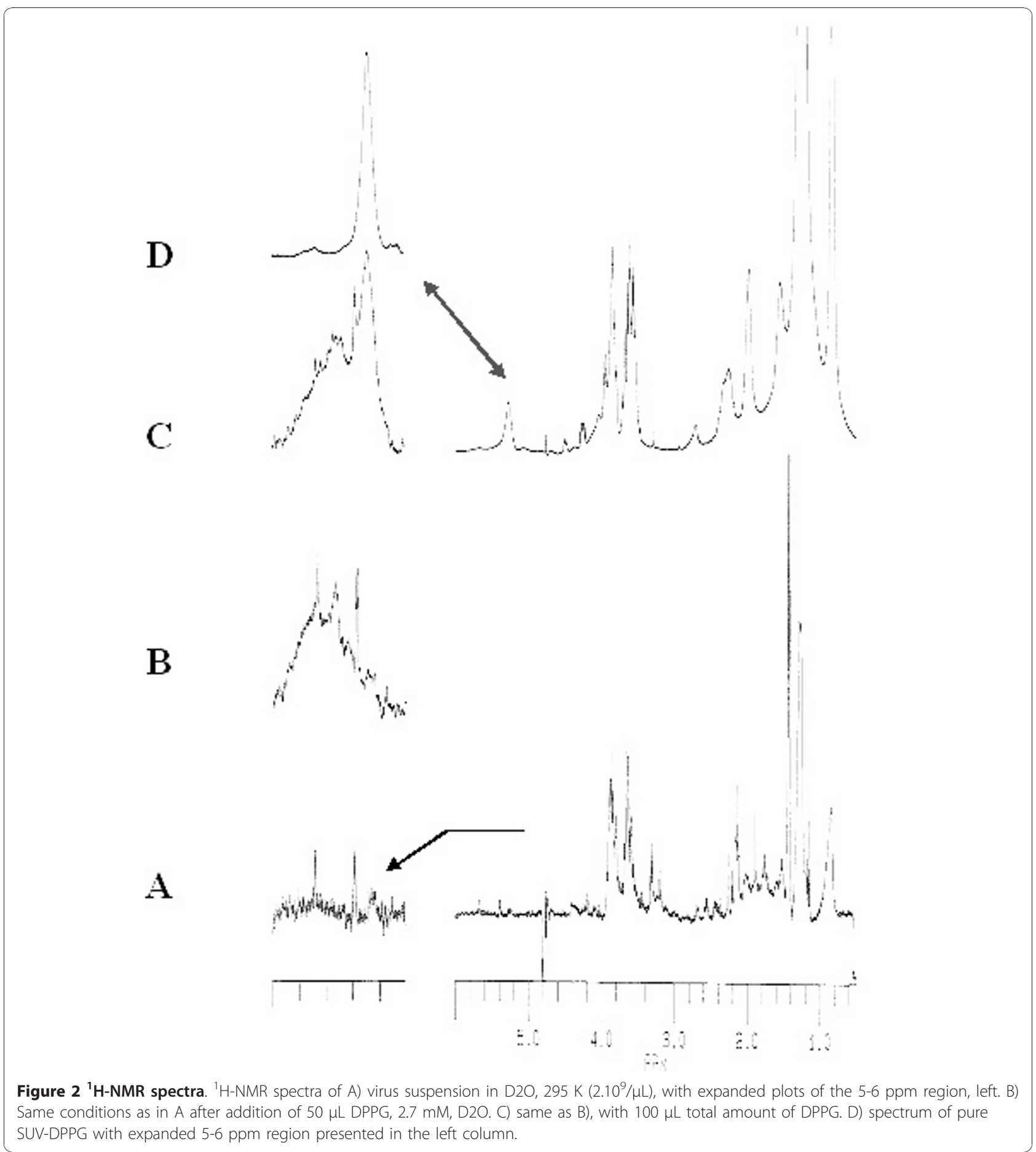

ensure that this group and consequently the polar head group of DPPG is involved in DPPG-VACV interactions.

\section{Stoichiometry estimation}

Using the starting concentration roughly extrapoled from the data in Figure 4 at $60 \mu \mathrm{L}$, an attempt to estimate the stoichiometry of the virus DPPG interactions was undertaken. Given the average cylindrical structure of the virus, considered as having a mean length of $350 \mathrm{~nm}$ and a radius of $175 \mathrm{~nm}$ [17], the total surface of the virus was estimated to be around $\mathbf{S v}=0.47 \boldsymbol{\mu m ^ { 2 }}$, $\left(4.710^{5} \mathrm{~nm}^{2}\right)$. Considering an estimation of the surface of a phospholipid around $S p \approx 0.6-0.7 \mathrm{~nm}^{2}$ (derived from the lecithin model), one can deduce for a 


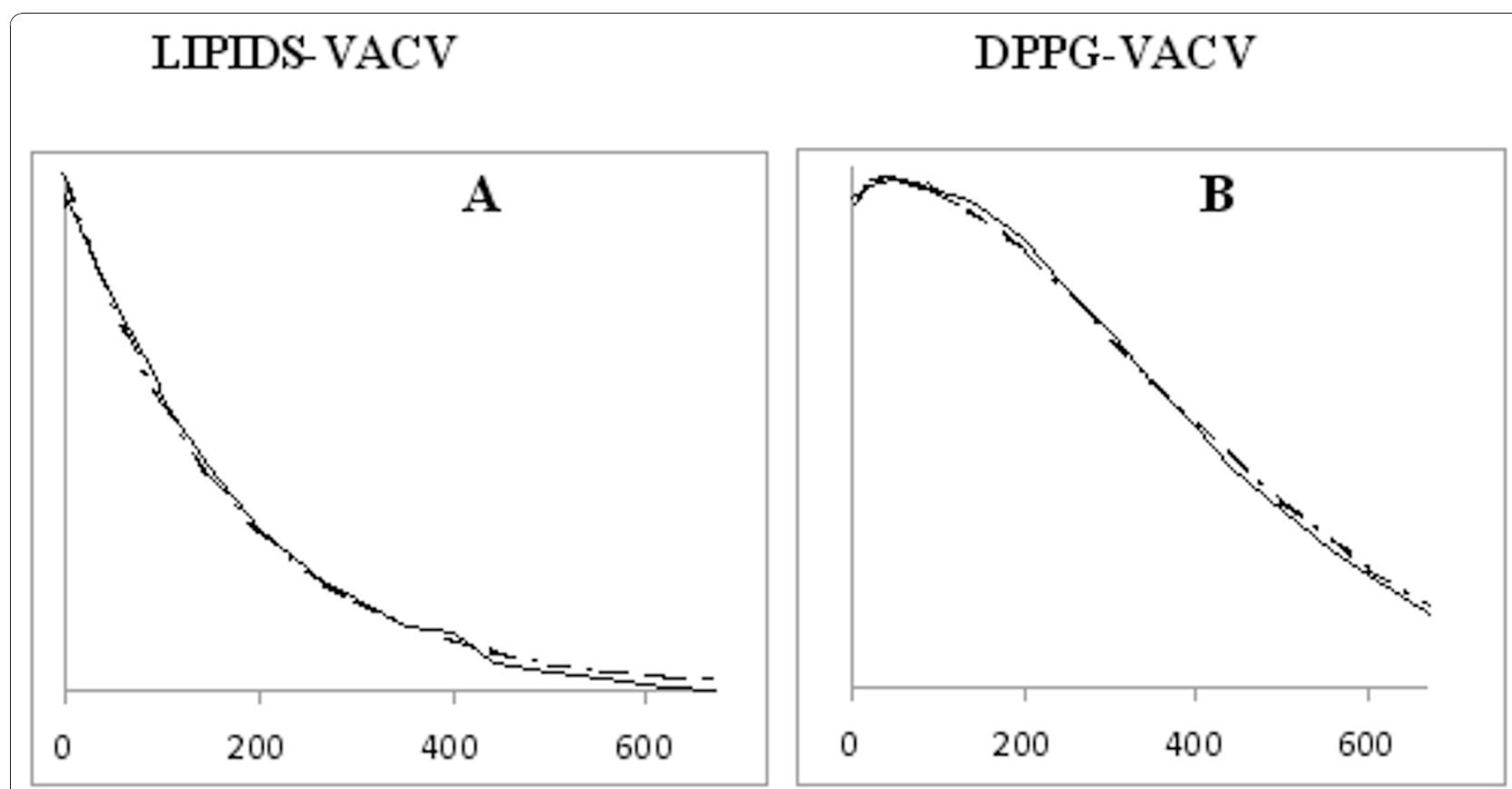

Figure 3 Peak to peak height evolution. Peak to peak height evolution measured on the central line of spectra as in Figure 1 after (15 $\mu \mathrm{L}, 0.2$ M) ascorbate addition for DPPC VACV-List sytems (A), and DPPG + VACV-List systems (B).

phospholipid concentration of $C=2.7 \mathrm{mM}$ in $\mathrm{D}_{2} \mathrm{O}, \boldsymbol{V}=$ $60 \mu \mathrm{L}$ added to the sample, the number of DPPG molecules added at this concentration:

$$
\mathbf{n}=\mathbf{N} * \mathbf{C} * \mathbf{S p} * \mathbf{V}
$$

with $\mathrm{N}=6.0210^{23}$, the Avogadro number

$$
\mathrm{n} \approx 10^{15} \text { molecules }
$$

Table 1 Numerical characteristics of the fits shown on the top traces. General formulae were $H(t)=H^{\circ}$. $\exp (-t / \tau)^{*} \cos$

\begin{tabular}{|c|c|c|c|c|}
\hline Phospholipid & Curve & $1 /$ Tau & Phase & Cosinus \\
\hline PC & monoexponential & 280 & - & - \\
\hline PC + VACV-WR & monoexponential & 180 & - & - \\
\hline PC + VACV-List & monoexponential & 227 & - & - \\
\hline Sulfatide & monoexponential & 250 & - & - \\
\hline Sulfatide + VACV-WR & monoexponential & 245 & - & - \\
\hline Sulfatide + VACV-List & monoexponential & 300 & & - \\
\hline DPPC & monoexponential & 350 & - & - \\
\hline DPPC + VACV-WR & monoexponential & 170 & - & - \\
\hline DPPC + VACV-List & monoexponential & 180 & - & - \\
\hline DPPG & monoexponential & 220 & - & - \\
\hline DPPG + VACV-WR & cosine $^{*}$ exponential & 430 & 0 & $2.9 \mathrm{E}-3^{*} \mathrm{t}$ \\
\hline DPPG + VACV-List & cosine $^{*}$ exponential & 286 & $-0,8$ & $2.7 \mathrm{E}-3^{*} \mathrm{t}$ \\
\hline
\end{tabular}
$($ a.t $+\varphi)$
This leads to a total surface ST of:

$$
\mathrm{ST}=\mathrm{Sp}^{*} \mathbf{n},
$$

$$
\mathrm{ST} \approx 710^{14} \mathrm{~nm}^{2}
$$

This allows an approximation of the number $\mathrm{Ne}$ of DPPG molecules involved in the interaction with the virus, assuming the absence of supramolecular structures remaining after SUV interactions:

$$
\mathrm{Ne}=\mathrm{ST} / \mathrm{Sv} \approx 1.510^{9} \mathrm{DPPG} / \text { virus }
$$

The result of this calculation appears somewhat unrealistic. Another way to calculate the stoichiometry is to consider the individual surface of a given headgroup on one hand (Sp), and the surface of the virus on the other hand (Sv). The maximum number of adducted headgroups would then be Na:

$$
\mathrm{Na}=\mathrm{Sv} / \mathrm{Sp} \approx 810^{5}
$$

Finally, SUV vesicles are well known to be very stable and dissymmetric structures, containing about $\mathbf{R}=$ $2-3000$ phospholipids per vesicle $(1 / 3$ in the internal layer, $2 / 3$ in the external layer). This feature, correlated with the discrepancy between the two calculations given in equations (5) and (6), indicates that supramolecular assemblies are still present even below the saturation, 


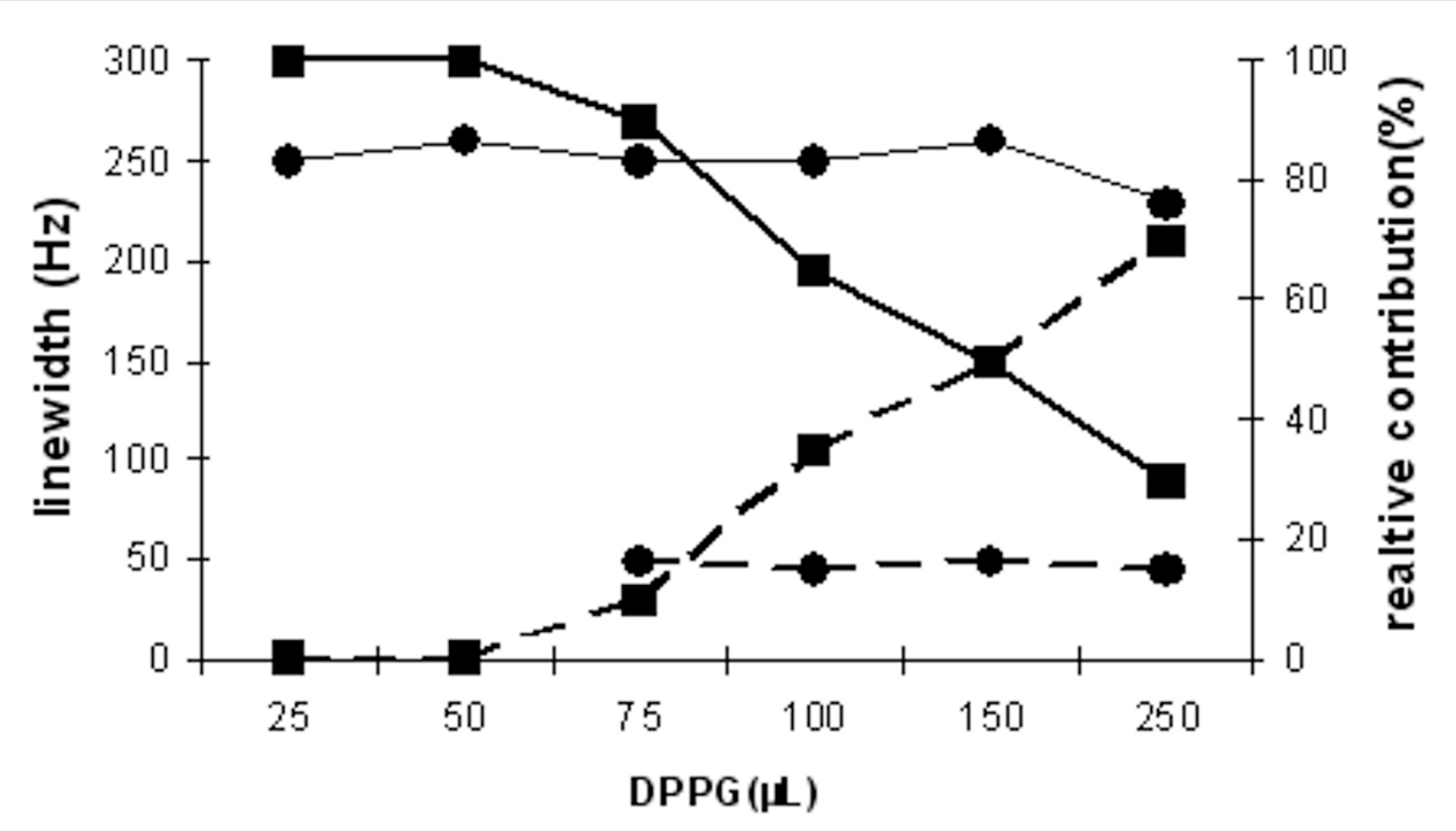

Figure 4 Plots of the linewidth (black circle, in $\mathrm{Hz}$ ) and of the relative contributions (black square, in \%) of the spectral components identified in the 5-6 ppm region.

since the $\mathbf{N a}^{*} \mathbf{R}$ product is in the same range as the $\mathbf{N e}$, ie $10^{9}$, with a difference of by a factor 3-4.

\section{Correlation with ESR results}

If one recalls the cosine ${ }^{*}$ exponential dependence of the nitroxide signal reduction in the presence of ascorbate, it appears that the exponential decrease results from a well known mechanism of nitroxide reduction in SUV, since the membrane embedded spin label exhibits local motions and exchanges with the surface, making it accessible to reduction (and de facto to signal intensity diminution). Moreover, the cosine function and more generally the circular function dependence, may reveal exchange processes [18] occurring between different states. Three systems are in presence: the vesicles, the aqueous system where ascorbate is soluble and the virus itself. Here, an initial increase of the signal precludes a direct access of nitroxide to ascorbate that would lead to immediate set up of the intensity reduction.

Direct SUV-VACV adducts all appear favorable to intra membrane exchanges of the label without any requirement for contact with the ascorbate-containing bulk. This motion would also result in ESR line narrowing, i.e. for a constant amount of spin label (integral of the peak) an increase of the measured peak-height as observed in the initial part of the DPPG-VACV ESR curves should occur.

\section{Conclusions}

When considering the respiratory route of contamination by VACV, the crossing of the surfactant barrier separating the respiratory lumen from cells lining alveoli is crucial [4]. The role of phosphatidylglycerol in the physico-chemical properties of surfactant was identified quite a while ago [19]. This study presents a systematic screening of the phospholipid-VACV interactions by the ESR method. This led us to identify an authentic interaction of glycerol bearing phospholipids with the virus and to use $1 \mathrm{H}-\mathrm{NMR}$ to obtain more precise information about this interaction. We propose that DPPG interacts with the virus surface without requiring an intermediate aqueous phase but rather a close contact of supramolecular assemblies, such as SUV, potentially allowing exchanges of small molecules embedded in the membranes, as suggested by the ESR spin label. This implies a mechanism that could allow virus to overcome the alveolo-capillary barrier.

\section{Acknowledgements}

This work was supported by the Service de Santé des Armées (SSA), the Délégation Générale pour l'Armement (DGA) and the association ARAMI. We thank Jean-Marc Crance for his support.

\section{Author details}

${ }^{1}$ Unité de biophysique cellulaire et moléculaire, CRSSA-IRBA, 24 avenue des maquis du Grésivaudan, 38702 La Tronche cedex France. ${ }^{2}$ Laboratoire de 


\section{Authors' contributions}

JCD designed the study, JP and ALF were involved in the study design. JP prepared purified virus. DC and JCD performed acquisition of data. JCD analyzed the data. ALF, JP and JCD wrote the draft of the manuscript. All authors read and approved the final manuscript.

\section{Competing interests}

The authors declare that they have no competing interests.

Received: 1 September 2010 Accepted: 31 December 2010

Published: 31 December 2010

\section{References}

1. Moss B: Poxvirus entry and membrane fusion. Virology 2006, 344:48-54.

2. Sherman IW: Twelve diseases that changed our world. Emerg Infect Dis 2008, 14:866.

3. Rooney SA, Young SL, Mendelson CR: Molecular and cellular processing of lung surfactant. FASEB J 1994, 8:957-967.

4. Veldhuizen R, Nag K, Orgeig S, Possmayer F: The role of lipids in pulmonary surfactant. Biochim Biophys Acta 1998, 1408:90-108.

5. Kingma PS, Whitsett JA: In defense of the lung: surfactant protein $A$ and surfactant protein D. Curr Opin Pharmacol 2006, 6:277-283.

6. Haagsman HP, Hogenkamp A, van Eijk M, Veldhuizen EJ: Surfactant collectins and innate immunity. Neonatology 2008, 93:288-294.

7. Postle AD, Gonzales LW, Bernhard W, Clark GT, Godinez MH, Godinez RI, Ballard PL: Lipidomics of cellular and secreted phospholipids from differentiated human fetal type II alveolar epithelial cells. J Lipid Res 2006, 47:1322-1331.

8. Balakireva L, Schoehn G, Thouvenin E, Chroboczek J: Binding of adenovirus capsid to dipalmitoyl phosphatidylcholine provides a novel pathway for virus entry. J Virol 2003, 77:4858-4866.

9. Favier AL, Burmeister WP, Chroboczek J: Unique physicochemical properties of human enteric Ad41 responsible for its survival and replication in the gastrointestinal tract. Virology 2004, 322:93-104.

10. Perino J, Crouzier D, Spehner D, Debouzy JC, Garin D, Crance JM, Favier AL: Lung surfactant DPPG phospholipid inhibits vaccinia virus infection. Antiviral Res 2010

11. Ludvikova V, Kutinova L, Simonova V, Otavova M: Evaluation of various virulence tests with low virulence vaccinia virus in mice. Biologicals 1994, 22:187-190.

12. Pailler $\mathrm{Y}$, Gadelle A, debouzy JC: hexakis (3,6-anhydro) tetrakis (2A,B,D,E-Obutyl) cyclomalto hexaose as a promising biological cation cryptant: Complexation and NMR study of interaction with membranes. Journal of drug delivery and science technology 2005, 15:237-244.

13. Mackett M, Smith G, Moss B: The construction and characterization of vaccinia virus recombinants expressing foreign genes. DNA cloning: $A$ Practical Approach 1985, 2:191-211.

14. Tsung K, Yim JH, Marti W, Buller RM, Norton JA: Gene expression and cytopathic effect of vaccinia virus inactivated by psoralen and longwave UV light. J Virol 1996, 70:165-171.

15. Debouzy JC, Neumann JM, Herve M, Daveloose D, Viret J, Apitz-Castro R: Interaction of antiaggregant molecule ajoene with membranes. An ESR and 1H, 2H, 31P-NMR study. Eur Biophys J 1989, 17:211-216.

16. Schwarz F: Méthodes statistiques à l'usage des médecins et biologistes. Flammarion médecine Sciences Ed, Paris 1981

17. Smith GL: Genus Orthopoxvirus: vaccinia virus. Poxviruses 2007, 1-45.

18. Masson P, Goldstein BN, Debouzy JC, Froment MT, Lockridge O, Schopfer LM: Damped oscillatory hysteretic behaviour of butyrylcholinesterase with benzoylcholine as substrate. Eur J Biochem 2004, 271:220-234.

19. White D, Fenner F: Medical Virology (3rd Ed). Orlando, Academic Press 1986.

doi:10.1186/1743-422X-7-379

Cite this article as: Debouzy et al:: ESR and NMR studies provide evidence that phosphatidyl glycerol specifically interacts with poxvirus membranes. Virology Journal 2010 7:379.

\section{Submit your next manuscript to BioMed Central and take full advantage of:}

- Convenient online submission

- Thorough peer review

- No space constraints or color figure charges

- Immediate publication on acceptance

- Inclusion in PubMed, CAS, Scopus and Google Scholar

- Research which is freely available for redistribution 